Indexaciones: Repositorio de Revistas UCR, DIALNET, Latindex, REDALYC Directorio y recolector de recursos digitales del Ministerio de Cultura de España, Directory of Open Access Journals. Diálogos Revista Electrónica de Historia ISSN 1409-469X. Número especial 2008. Dirección web: http://historia.fcs.ucr.ac.cr/dialogos.htm

\title{
De La Puebla a La Carpio: segregación y exclusión en la ciudad de San José
}

\author{
Raúl García Fernández \\ Sociólogo. Consultor independiente. \\ jraulgarciaf@yahoo.es
}

Laura Paniagua Arguedas

Socióloga. Investigadora asociada en el Instituto de Investigaciones Sociales de la Universidad de Costa Rica y en el ILANUD. laura@iis.ucr.ac.cr, 2207-3301

1 Queremos agradecer profundamente a Carlos Sandoval por el apoyo y por compartir sus sugerencias e inquietudes que motivaron la realización de este trabajo. Agradecemos también a Elías Zeledón y a Dennis Arias por facilitar la localización de fuentes de información. 


\section{Introducción}

La ciudad constituye un conjunto de vínculos, intercambios, edificaciones, espacios públicos y privados, sensaciones, sistemas de producción, conflictos, luchas y acciones en las que tiene lugar y se plasma el ejercicio del poder de los diferentes sectores que componen la vida en sociedad.

A lo largo de su historia, en la ciudad de San José la configuración del espacio urbano ha estado atravesada por conflictos económicos, sociopolíticos y culturales, los cuales se han materializado en una segregación espacial estrechamente vinculada con las demandas de los proyectos económicos de cada época y a la exclusión social producida por los mismos.

Esta ponencia tiene como objetivo explorar las formas en las cuales se fue configurando la segregación social y espacial en la ciudad de San José, a través de procesos de diferenciación y exclusión promovidos desde los proyectos de las élites del momento.

Para estos fines, se propone indagar en el establecimiento de la exclusión en el espacio urbano a través de la revisión de la distribución o acumulación de recursos e infraestructura en los comienzos de la ciudad y en la actualidad.

Si bien las condiciones de vida de los sectores populares, las viviendas, la residencia en cuarterías, pasajes o patios se encuentran presentes en la historia de la ciudad y sus barrios, y fue de preocupación y vigilancia de las autoridades de policía y salubridad en las distintas épocas, éstas exceden las preguntas planteadas por este trabajo. ${ }^{2}$ Sin embargo, cabe dejar planteado que la temática de la segregación, la exclusión social y la vivienda se encuentran estrechamente relacionadas.

La guía en esta reflexión será el espacio de la ciudad de San José y a través del mismo recorreremos algunas formas en las cuales ha sido asentada la segregación. Se dará énfasis al establecimiento de "barrios populares", pero interesa indagar sobre las formas en las cuales esos lugares han sido estigmatizados, pues desde el discurso de las élites y de otros sectores que ejercen el poder se les

2 Algunos trabajos importantes que abordan esta temática lo constituyen: William Elizondo, "Vivienda y pobreza en la ciudad de San José en la década de 1920", Anuario de Estudios Centroamericanos (Costa Rica) 1-2, n. 24 (1998). Carlos Salas, Análisis histórico-social de nuestros tugurios en el siglo XX. (San José, Costa Rica: Tesis de Licenciatura en Historia, Universidad de Costa Rica, 1976). César Briceño; William Elizondo; Javier Rodríguez y María Auxiliadora Vega. Pobreza urbana en Costa Rica 1890-1930. El caso de la ciudad de San José. (San José, Costa Rica: Memoria de Seminario de Graduación. Licenciatura en Historia. Universidad de Costa Rica. 1998). 
designan calificativos y se les caracteriza de forma estereotipada, atribuyéndoles peligrosidad ya sea para la salud, la limpieza o para la seguridad del cuerpo físico y social de la ciudad.

El recorrido parte del establecimiento de La Puebla como el primer sitio para excluidos en la ciudad de San José y finaliza en La Carpio, espacio que en su representación simbólica provoca actualmente percepciones muy similares a las que podría haber despertado el primer lugar mencionado.

Se escogió a la ciudad de San José para la indagación por ser un espacio urbano con particularidades históricas importantes. En palabras de Steven Palmer, "San José es la única ciudad preeminente en la Centroamérica decimonónica que no tuvo sus orígenes en el siglo XVI (a parte, por supuesto, del caso anómalo de la nueva Ciudad de Guatemala)"; ${ }^{3}$ en ese sentido, el autor indica que las principales ciudades de América Latina se instauraron en lugares donde se estableció el poder colonial, mientras que San José tiene su auge en el siglo XIX. Otra razón es que esta ciudad se consolidó como "el centro" de la política, la cultura, el comercio, los servicios y la producción agroexportadora ${ }^{4}$ de una época, por ser la actual capital de Costa Rica y contar dentro de su historia con claras tendencias segregacionistas en términos de clase social.

Además, diferencia de otras capitales y ciudades centroamericanas, las características de la segregación de la ciudad de San José, parecen marcar una predominancia en términos de clase social a diferencia de otras ciudades en Costa Rica (Cartago, Heredia) y la región en las cuales la segregación se dio originalmente en términos étnicos, estrechamente vinculados al acceso a recursos económicos.

El documento se encuentra dividido en tres apartados, como se refiere a continuación: 1. la conformación histórica de sitios para población excluida en la ciudad de San José y la segregación en relación con la composición de clase social de cada población; 2. la constitución histórica y simbólica de la segregación en "el Sur" y la construcción de discursos sobre la exclusión y los excluidos 3. y, las aspiraciones de la élite en la actualidad, con la ciudad neoliberal, espacio destinado a acoger el esquema del actual proyecto económico.

Un aspecto fundamental que motivó la realización de este trabajo se vincula con las implicaciones biográficas que poseen para sus autores los espacios "al sur" a los cuales se hará referencia. Se espera que los aportes aquí apuntados sean motivo de nuevas preguntas y de otras investigaciones

3 Steven Palmer, "Prolegómenos a toda historia futura de San José, Costa Rica", Mesoamérica (Costa Rica) 31 (junio 1996): 191.

$4 \quad$ Ibid., 198. 
en torno a este espacio de la ciudad históricamente olvidado.

\section{La conformación histórica de exclusión en la ciudad}

La ciudad de San José ha experimentado diferentes procesos de urbanización, los cuales han sido promovidos por los proyectos económicos de las clases dominantes de cada época. En ese sentido cobra relevancia rastrear espacial y temporalmente el establecimiento de una geografía de la exclusión ${ }^{5}$, en el sentido de cómo los conflictos sobre el espacio han culminado en una distribución diferenciada según la clase social.

En términos generales el espacio es uno de los recursos más importantes en el cual se inscribe el poder. Es por eso que el espacio es eminentemente político, en el mismo es posible leer las diferenciaciones sociales, la exclusión y la violencia de una sociedad. Las decisiones que definen quienes se ubican en determinados sectores y quiénes toman esas decisiones también se configuran en el espacio de la ciudad.

Para revisar esa geografía de la exclusión se hace necesario indagar sobre las formas de segregación que se dan en el territorio. Para Francine Dansereau, existen tres formas en las cuales ha sido analizada la segregación:

- definida de una manera descriptiva para evidenciar la concentración en el espacio urbano de hogares pertenecientes a categorías sociales semejantes (según etnia, clase social, etc.),

- planteada como segregación espacial, con un acceso desigual a los servicios públicos y equipamientos colectivos,

- y, vista como una estrategia de exclusión del espacio, para distanciar a ciertos grupos sociales sobre la base de una diferenciación. ${ }^{6}$

En este trabajo, se hará una pequeña revisión de estas instancias comprendiendo que en la segregación se dan estas manifestaciones interconectadas; asimismo, muchos espacios segregados presentan no sólo dificultades en el acceso a servicios sino, además, la colocación de infraestructura o lugares considerados "indeseables", como botaderos de basura, industrias químicas, plantas de procesamiento de aguas residuales o químicas, etc. Por su parte, cabe señalar

$5 \quad$ Wolfgang Hein y Edgar Fürst, "Turismo en la era de globalización: implicaciones de equidad para la sociedad y el ambiente internacional", en Turismo de larga distancia y desarrollo regional en Costa Rica: estudios sobre las relaciones económico-ecológicas entre turismo y desarrollo sostenible en los ámbitos globales, nacionales y micro-regionales, ed. Wolfgang Hein y Edgar Fürst (San José, Costa Rica: DEI, 2002 ), 90 .

6 Anne-Marie Séguin ed., La Segregación socio-espacial urbana: una mirada sobre Puebla, Puerto

España, San José y San Salvador (San José, Costa Rica: FLACSO, 2006), 32-33. 
que la segregación no refiere únicamente a la existencia de barrios populares o en exclusión social, sino que también responde a formas de autosegregación propiciadas por urbanizaciones, barrios cerrados o condominios, que responden a las formas de uso del espacio por parte de los sectores de mayor concentración de riqueza.

Desde el surgimiento de San José se han establecido espacios para determinados sectores. La distribución en el espacio urbano ha correspondido a los procesos económicos característicos de cada período. De esta manera, la ciudad ha contado con barrios excluidos y exclusivos, claramente delimitados entre sí. Las nociones de centro y márgenes enuncian esas diferenciaciones en formas en las cuales se construyen ideas sobre "lo marginal" y "los marginales".

Desde la colonia, pasando por los primeros años de economía capitalista y su consolidación con el proyecto liberal, las décadas de influencia política socialdemócrata y hasta llegar al período neoliberal la ciudad ha experimentado políticas municipales y de gobierno las cuales han llevado al mantenimiento o cambio en su configuración y conformación. Dentro de los proyectos de las élites la presión sobre el uso del territorio ha generado la segregación social de la ciudad regida por el incremento en los alquileres y la especulación inmobiliaria, así como el desarrollo de proyectos e infraestructura a cargo de los municipios.

En 1932, Carmen Lyra (María Isabel Carvajal) y Luisa González describen en el semanario Trabajo la conformación de esa ciudad segregada y nos presentan una panorámica general del tema que nos ocupa en esta ponencia:

“...[i Son de admirar!] La calle de la Estación del Atlántico, el Barrio Amón, el Barrio Otoya, el Barrio González Lahmann, el Paseo Colón y La Sabana. El Paseo Colón, sobre todo, con el aspecto de sala de nuevo rico que ahora ha cogido con tanta pérgola, tanto farol, tanta banca y tanto obelisco. Son los lugares de presumir de San José". Todo cambia si nos alejamos hacia cualquiera de los puntos cardinales, "sobre todo hacia el sur, en donde el suelo es arcilloso y por consiguiente muy húmedo". Lugares así son: San Francisco de Guadalupe, Cinco Esquinas, Calle Blancos, las casuchas de los lotes Volio, "la especie de palomar" por la pulpería "El Dólar" perteneciente a Traube, "en donde pulula una población sucia y mísera"; "el barranco que pertenece a la sucesión del Dr. Valverde por el Paso de la Vaca"; el barrio detrás de la Penitenciaría; el B ${ }^{\circ}$ México, La Pitahaya, Keith, Constructora, Carit, Luna Park, Turrujal, Luján "y los barrios construidos por la Cruz Roja Costarricense, que siempre ha estado en manos de 
burgueses que quieren pasar por personas de buen corazón...".7

Tal como lo refleja este recorrido espacial en el San José de los años treinta, en la ciudad es posible leer la distribución del espacio, servicios, estética, condiciones geológicas, e inclusive el "nombre", marcadamente diferenciados en términos de clase social.

Por un lado, el sistema capitalista requiere de la ubicación cercana a los centros de producción de sectores proletarizados, por otro lado, los dueños del capital buscan ubicarse cerca de los centros urbanos, de recreación y de los lugares con mejor acceso a los recursos vitales, como el agua.

De allí surge la pregunta sobre cómo se fue configurando históricamente esa segregación en San José, y para ello es necesario remitirnos un poco más atrás a los orígenes mismos de esa ciudad.

El surgimiento de San José data del siglo XVIII. Según Cleto González Víquez la primera ermita de la Boca del Monte se construyó hacia 1738. En 1755, el alcalde ordinario de Cartago, Tomás López Corral, amenazó con una multa significativa a la población que se negara a residir permanentemente en el lugar. ${ }^{8}$ Esto nos indica que el origen fue en sí mismo promovido por coerción.

Según Steven Palmer, la Villa Nueva constituyó una ciudad con su plaza principal, alineada por los cuatro puntos cardinales, con su catedral y su cuartel y sus calles saliendo de la plaza en ángulos rectos. ${ }^{9}$ La segregación que tuvo lugar presentaba en el espacio la distribución social de clase y la ubicación de fuentes de agua definió el establecimiento en cada sector: "los sectores "acomodados" ubicaron sus residencias y edificios principales de gobierno precisamente entre las que son hoy las avenidas central y primera, paralelo a la acequia que se construyó en 1751, que al parecer fue tomada desde la naciente de la quebrada de Las Arias [cerca de la antigua aduana]. La Puebla se formó más al sur, donde corría otra quebrada hacia el oeste [quebrada Lantisco], donde podían abastecerse de otras fuentes de agua, pero no tan cerca de la ermita como aquellos otros". ${ }^{10}$

De esta forma, la futura metrópoli creció a lo largo del siglo XIX hasta al menos 1850, con una

$7 \quad$ Trabajo, 21 de abril de 1932, en: José Manuel Cerdas, Condiciones de vida de los trabajadores industriales de San José. 1930-1960. (Tesis de Maestría en Historia, Universidad de Costa Rica, 1994), 288.

8 Palmer, "Prolegómenos", 190.

9 Palmer, "Prolegómenos", 189.

10 César Briceño; William Elizondo; Javier Rodríguez y María Auxiliadora Vega, Pobreza urbana en Costa Rica 1890-1930. El caso de la ciudad de San José (San José: Costa Rica, Memoria de Seminario de Graduación. Licenciatura en Historia. Universidad de Costa Rica, 1998), 107. 
marcada jerarquización del espacio, desde la plaza central y sus alrededores, predominando la estructura colonial. "Cuanto más lejos de este círculo de poder, más fragmentados fueron los lotes y menos poder económico tenían sus moradores...". ${ }^{11}$

Diversas investigaciones coinciden en la ubicación al sur de la ciudad a los barrios más empobrecidos y excluidos. A ese sector sur se le dio el nombre de La Puebla, la cual aparece mencionada en documentos desde $1759 .{ }^{12}$ Posteriormente, con el transcurso de los años también se ubicaron en el noroeste algunos asentamientos de población con similar extracción social.

Con la Ley de Bases y Garantías se da una distribución de la ciudad en cuarteles. En 1841 se establecen dos barrios con sus respectivos cuarteles: Carmen (Cuarteles de Chorro, Parroquia, Plaza Mayor, Puebla y Panteón) y Merced (Laguna, Cabildo, Ballestero, Factoría y Paso de la Vaca). ${ }^{13}$ Muchos de los nombres de dichos cuarteles provenían de los barrios ya existentes y permanecerían posteriormente por mucho tiempo.

Según Steven Palmer, al inicio de la segunda mitad del siglo XIX se empieza a constituir una cultura burguesa, la cual buscó diferenciarse de la cultura de los grupos populares urbanos de artesanos y jornaleros y de los trabajadores rurales. Los cambios en los patrones de consumo y comportamiento, los valores y actitudes hacia la familia y la adopción de ideologías modernas (como el liberalismo) y religiones modernas (la masonería) fueron reflejo de esa nueva "cultura"; asimismo, el nacionalismo sería utilizado a finales de ese siglo con el objetivo de "retejer la comunidad política en el plano imaginario". ${ }^{14}$ Esas transformaciones culturales tuvieron su asidero en el espacio, como lo plantea Patricia Fumero:

“...la ciudad de San José en 1850 ya mostraba características de ciudad moderna y había redefinido su espacio geográfico de la siguiente forma: al norte se construyeron los barrios populares de Paso de la Vaca y la Factoría. Al suroeste, se encontraban las barriadas de los habitantes de menores recursos, básicamente compuestos por artesanos y obreros: La Puebla, El Laberinto, El Chorro y El Panteón. Finalmente, a finales del siglo XIX se inició un proceso de traslado de las élites de los alrededores de la Catedral hacia el sector noreste (barrio Amón a partir de 1897) y al oeste (Paseo Colón) de la ciudad. Esta segmentación del espacio urbano josefino se consolidó

11 Florencia Quesada, La modernización entre cafetales. San José, Costa Rica, 1880-1930 (Tesis doctoral Facultad de Humanidades de la Universidad de Helsinki, Instituto Reenvía, 2007), 46.

12 Ibid., 30.

13 Quesada, "La modernización”, 46.

14 Palmer, "Prolegómenos", 202. 
entre 1890 у $1930 \ldots . .15$

La década de 1880 va a incorporar cambios significativos en la diferenciación espacial, como indica Palmer, a través de un "indicador simbólico-social se da un desplazamiento", el mercado se traslada a donde se encuentra actualmente y se convierte en "higiénico, supervisable y diariamente operativo"; asimismo, como lo indicó Fumero, la burguesía se traslada hacia el extremo noreste de la ciudad. ${ }^{16}$ Así el "centro se consolidó como tal, modificando su rol de asiento de residencia de los acaudalados, que se trasladaban a vivir a barrios estilo Amón, a centro comercial y administrativo del país". ${ }^{17}$ En 1889 el cuadrante citadino se duplica (153 manzanas), proceso que ocurrió en tan sólo tres décadas. ${ }^{18}$

Para comprender estas transformaciones es necesario remitirse a la presencia de los liberales en el poder y las políticas que ejecutaron, promovidas por el espíritu del progreso positivista y de la higiene pública que incentivaron el cambio y renovación citadina dando inicio de la modernización urbana en la capital: ${ }^{19}$

“...la ciudad crecía y se transformaba, el "progreso" no fue uniforme sino más bien, selectivo geográfica y socialmente (...) La deliberada segregación del espacio urbano que se inicia en este período, tuvo como consecuencia la creación en sus extremos de dos ciudades, una la San José burguesa de renovados parques, arquitectura ecléctica comercial y privada, servicios públicos y nueva infraestructura; la ciudad "moderna" a lo largo de la Avenida Central, los parques Morazán, Nacional y La Sabana. La otra ciudad que creció sobre todo al sur y al noroeste, la San José popular que comenzaba a conformarse y a quedar geográficamente segregada y rezagada (...) La ciudad marginal, foco de atención de los inspectores sanitarios en su intento de transformar no sólo el espacio físico sino a sus habitantes...”. ${ }^{20}$

Desde su origen y hasta 1870, San José se caracterizó por la dispersión. Durante el siglo XIX, parece experimentar "...una sola fase significativa de cambio espacial, y esto no empezó sino

15 Patricia Fumero, El advenimiento de la modernidad en Costa Rica: 1850-1914 (San José, Costa Rica:

Editorial Universidad de Costa Rica, 2005), 7.

16 Palmer, "Prolegómenos", 203.

17 Luis Guillermo Salazar, Formación del espacio social de la ciudad de San José: proceso de apropiación del territorio urbano (1870-1930) (Tesis de maestría en Sociología. Universidad de Costa Rica, 1986), 87.

18 José Manuel Cerdas, Condiciones de vida de los trabajadores industriales de San José. 1930-1960.

(Tesis de Maestría en Historia. Universidad de Costa Rica, 1994), 270.

19 Quesada, "La modernización”, 71.

20 Ibid. 
hasta 1870 cuando la riqueza cafetalera era extremadamente madura..... ${ }^{21}$ En 1881 la segregación fue respaldada por las medidas tomadas por el clero. El Curato de San José se dividió en dos parroquias según la conformación social de cada barrio: Nuestra Señora de la Merced, cerca de La Puebla y Nuestra Señora del Carmen, en el distrito de aquel nombre. ${ }^{22}$

Los edificios principales de gobierno y administración, así como las residencias de las familias adineradas se ubicaron hacia el centro y el sector noreste de la ciudad; al menos noventa cafetaleros tenían grandes casas en San José y un 13\% de los lotes urbanos estaban en manos de esta elite, situados en su mayor parte alrededor de la plaza central de San José. ${ }^{23}$

De esa manera, los distritos del Carmen y Catedral fueron el lugar en el cual se establecieron los barrios exclusivos desde los orígenes de la ciudad. A partir de 1897, las familias de la burguesía josefina se ubicaron en los barrios Amón, Otoya y Aranjuez, así como al noreste del distrito Catedral (González Lahmann). La población residente en estos barrios contó desde el principio con los servicios y privilegios de la época, como electricidad (en calles y residencias), agua, aceras y otros elementos de arquitectura y recreación: el ferrocarril al Atlántico, el Parque Nacional, el Paseo de las Damas, el Parque Morazán, el Parque Bolívar, la Biblioteca Nacional, el Teatro Variedades, el Teatro Nacional. Primeramente, hacia el sur se ubicaron pequeñas casas y fueron brindados los servicios y demás condiciones para la vida de sus habitantes, mucho tiempo después. ${ }^{24}$

Con este desplazamiento de la burguesía en el espacio de la ciudad (hacia el Barrio Amón) se produjo "el abandono de la ciudad patricia y los inicios de la ciudad masificada". ${ }^{25}$ El distrito del Carmen fue el distrito de élite josefina. En ese lugar se ubicaron las edificaciones políticas, económicas y culturales de la burguesía de la época y fue el distrito con el valor más elevado en el uso del suelo.

En el Carmen no se ubicaba ningún barrio excluido; únicamente se encontró registro de un lugar denominado "El Palomar", constituido por las viviendas de las lavanderas que trabajaban para las familias de Barrio Amón, "eran una serie de cuartos donde estas mujeres y sus familias

$21 \quad$ Palmer, "Prolegómenos", 198.

22 Yanory Álvarez y Dennis Gómez, San José de antaño. Distrito Catedral (1890-1940) (San José, Costa Rica: Ministerio de Cultura, Juventud y Deportes, Centro de Investigación y Conservación del Patrimonio Cultural, 2000), 80.

23 Quesada, "La modernización”, 46.

24 Álvarez y Gómez, "San José de antaño", 80.

25 Palmer, "Prolegómenos", 210. 
vivían en condiciones de hacinamiento", ${ }^{26}$ cuarterías ubicadas "en un terreno de gran pendiente, al costado sur de los lavaderos". ${ }^{27}$ Esta ubicación se refiere a los Lavaderos del Padre Umaña construidos en 1870 por la donación de los terrenos de parte del sacerdote, ubicados entre las actuales calle 1 y 3 en el bajo de Amón. ${ }^{28}$

Aunque el caso del distrito Carmen se percibe la tendencia exclusión, el distrito Catedral en sus orígenes estuvo conformado por grupos de habitantes bastante heterogéneos:

“...En los sectores inmediatos a las iglesias se construyeron viviendas con todas las características de las residencias de personas de altos ingresos. Hacia el sur, se ubicaron gran cantidad de artesanos y obreros, siendo común observar en esa zona pequeños talleres de sastres, zapateros, ebanistas, herreros, floristerías, y pequeñas industrias de jabón, siropes, velas, cigarrillos y licores, alternando con las opulentas edificaciones (...) Algunas viviendas albergaban en la primera planta, prósperos negocios, y en la segunda la residencia de sus propietarios, situación que gradualmente se fue transformando....". 29

Los sectores obreros, empobrecidos y excluidos se fueron ubicando fundamentalmente en los actuales distritos Hospital y Merced, los cuales, especialmente el primero, albergarían a los barrios "más pobres y poblados de la capital" ${ }^{30}$ En San José, desde el siglo XIX, se encuentran, junto con La Puebla, barrios como: el Barranco, Peor es Nada, Las Latas, El Chorro, Gracias a Dios, Calle del Panteón, La Pólvora y los caseríos o patios: Patio de los Mena, de los Soto. ${ }^{31} \mathrm{Al}$ distrito Hospital pertenecían: La Puebla, Barrio Santa Lucía, la Constructora, Barrio Keith, lotes Carit y Pacífico. ${ }^{32} \mathrm{Al}$ sur del distrito Catedral se conformarían Chile de Perro y Turrujal (luego Barrio Luján); luego, a finales del siglo XIX y principios del XX, surgen Colección (luego Plaza Víquez), El Laberinto (el Pacífico), Barrio Güell.

De esta forma suroeste y una parte del noroeste se consolidaron como las zonas excluidas aunque, al igual que en Catedral, también existían barrios de clase media, artesanos y peones. El sector 26 Briceño y otros, "Pobreza urbana", 109.

27 Gerardo Vargas y Carlos Zamora, El patrimonio histórico-arquitectónico y el desarrollo urbano del distrito Carmen de la ciudad de San José 1850-1930 (San José, Costa Rica: Ministerio de Cultura, Juventud y Deportes, Editorial de la Dirección de Publicaciones, Centro de Investigación y Conservación del Patrimonio Cultural, 1999), 108.

28 Ibid.

29 Álvarez y Gómez, "San José de antaño", 54.

30 Briceño y otros, "Pobreza urbana", 105.

31 Carlos Naranjo y Mayela Solano, El delito en la provincia de San José 1870-1900 (Tesis Licenciatura en Historia, Heredia, Costa Rica: Universidad Nacional, 1989), 31.

32 Briceño y otros, "Pobreza urbana", 108. 
al norte y al oeste del mercado era el sitio de la segunda fase de crecimiento de barrios populares en San José, principalmente a partir de 1900, también mezclados con otros sectores sociales y con una pobreza generalizada: ${ }^{33}$

"Como clase social, los trabajadores josefinos residían en una gama más o menos amplia de barrios, acordes al ingreso familiar. En los barrios más bajos convivían con los subempleados, desempleados y el "lumpen". En los barrios populares mejor acomodados, los trabajadores corresidían con empleados, pequeños y medianos comerciantes y otros grupos de ingreso medio." ${ }^{34}$

Retomando las reflexiones sobre el espacio que rescatamos al inicio de este apartado en palabras de Carmen Lyra y Luisa González, en San José para la primera mitad del siglo XX encontramos la consolidación de lo que se denominó "Barrio del Sur", como una forma de englobar todo el sector sur de la ciudad que en términos simbólicos y materiales fue vinculado con pobreza, vicio y contaminación.

A partir de 1950 se dio un proceso de urbanización masiva en la ciudad de San José35, la capital se encontraba inmersa en el proceso de industrialización. Desde esa época eran concebidos como "Barrios del Sur": Barrio Cuba, Barrio Keith (luego Cristo Rey), Sagrada Familia, Salubridad, Lotes Mongito, Paso Ancho, San Sebastián, Hatillo, Lomas de Ocloro, Y Griega, Santa Marta, Tiribí y El Cerrito. ${ }^{36}$ Algunas zonas de exclusión se encontraban en los barrios mencionados y en otras ubicaciones de la urbe: Calle Chapulines (en Curridabat), Corazón de Jesús (Uruca), Torremolinos (Paso Ancho), Pasaje Jiménez, Pasaje Valverde, Pasaje Rodríguez, Pasaje del Capitolio, Patios del Cerrito (Barrio Luján), Bajos de Calle Morenos, Bajos del Torres, Bajo de los Piuses (Tibás), Bajos de Los Anonos.

Un rasgo fundamental de un lugar, lo constituye cómo es nombrado o designado, y precisamente en el nombre es posible acercarse a la forma en la cual en el espacio es plasmada la segregación y el ejercicio del poder. Los barrios populares son nombrados por el poder (La Puebla); por circunstancias contextuales (El Cerrito, el Barranco, Peor es Nada, Las Latas, Calle del Panteón,

33 Palmer, "Prolegómenos", 203.

34 Cerdas, "Condiciones de vida", 286.

35 Iván Molina, “Una metrópolis en miniatura. Introducción”, en Del viejo San José, comp. Elías Zeledón

(San José, Costa Rica: Editorial de la Universidad de Costa Rica, 2004), xiii.

36 Informes de las personas que habitan en ranchos y chinchorros levantados debajo de los puentes Torres, Virilla y Anonos, en orillas de calle o en terrenos municipales y algunos pasajes de esta capital. En: Ministerio de Trabajo, Tugurios (San José, Costa Rica: Ministerio de Trabajo, Departamento de Previsión Social, 1954). 
La Pólvora); por hechos ocurridos en el lugar (probablemente La Puñalada); o con el nombre de los dueños o donantes del terreno (Pasaje Jiménez, Carit, Keith). En el caso de los barrios de la élite, éstos son llamados con los apellidos de las familias adineradas del lugar (Amón, Otoya, Aranjuez).

Como una síntesis de esos procesos, José Manuel Cerdas indica que entre 1930 y 1960:

- San José se expandía rápidamente, manteniendo un proceso de segregación socioespacial,

- los rasgos rurales se fueron desplazando hacia la periferia de los cuatro distritos centrales, la concentración o hacinamiento de las edificaciones se veía interrumpido por los solares desocupados y los patios y traspatios de las casas,

- la infraestructura y los servicios de pavimentado, transporte, electrificación, acueductos y alcantarillado se desenvolvieron aunque no con la prontitud deseada por los sectores más necesitados, los barrios populares o marginados,

- la clase trabajadora, particularmente del sector secundario (industria y construcción), con niveles de vida diversos a su interior, diversas eran las áreas capitalinas que ocupaba; tuvo contacto con sectores muy pobres y en otros espacios con capas medias,

- los barrios populares donde residían los trabajadores estaban bien distinguidos de los barrios de la burguesía, y entre ambos habían espacios intermedios donde habitaban obreros y artesanos. ${ }^{37}$

Los barrios populares mencionados fueron habitados por los sectores excluidos de la sociedad y su origen ha tenido un importante vínculo con la migración; es decir, los grupos expulsados de las dinámicas productivas en las diferentes zonas de Costa Rica y otros países, personas que emigraron de comunidades rurales procurando hallar mejores condiciones de vida en la ciudad. Durante la segunda mitad del siglo XX proliferaron proyectos de vivienda de interés social y se dio una institucionalización de la situación habitacional de los sectores populares y empobrecidos, con la creación de entidades como el Instituto Nacional de Vivienda y Urbanismo INVU (1954), el Instituto Mixto de Ayuda Social (1971), el Banco Hipotecario de la Vivienda y el Ministerio de Vivienda y Asentamientos Humanos. ${ }^{38}$ Parece ser que durante el periodo socialdemócrata, la 37 Cerdas, "Condiciones de vida", 292-293.

38 William Elizondo, "El problema de vivienda: Segregación y pobreza urbana en la primera mitad del siglo XX en Costa Rica”, en Pobreza e historia en Costa Rica. Determinantes estructurales y representaciones sociales del siglo XVIII a 1950, ed. Ronny Viales (San José, Costa Rica: Editorial de la Universidad de Costa Rica, 2005), 156. 
élite dejó de pensar en la ciudad como centro de ejercicio o instauración de su poder.

Desde los años 80, conforme se fueron incrementando las desigualdades sociales, los grupos de élite se empezaron a ubicar en zonas alejadas del centro de San José, y proliferaron los barrios autosegregados (comunidades cerradas o urbanizaciones).

A finales del siglo XX y principios del XXI, se busca incentivar el regreso de la élite a la ciudad capital, por lo cual se empiezan a generar cambios que resulten atrayentes con el fin de construir nuevamente espacios exclusivos.

\section{“Barrios del Sur”: recursos y discursos acerca de la exclusión}

El presente apartado establece algunos datos relevantes sobre la constitución en el sector sur de la ciudad de San José de los espacios para excluidos, de esta forma se establece un interés por indagar en los orígenes históricos y simbólicos de la segregación en la construcción de las ideas estigmatizantes acerca de "Barrios del Sur".

El identificar a los sectores populares de la ciudad utilizando como referencia el punto geográfico del sur, parece ser de larga data. Por ejemplo, en 1893 “vecinos de Hatillo, San Sebastián, Alajuelita y población del Sur" solicitaron a la Secretaría Municipal de San José el establecimiento de una Botica en el punto "La Puebla". ${ }^{39}$ Lo importante a destacar es que este referente no marca tanto una ubicación, sino la diferenciación con respecto a otro sector de la ciudad: el norte (físicamente el centro y noreste), construido como el espacio de "desarrollo", "progreso", "cultura" e ideales urbanos. Es decir, "Barrios del Sur" responde más a un lugar dado a los sectores excluidos desde el poder dentro de la geografía de la exclusión.

El primer "Barrio del Sur" de la capital lo constituyó La Puebla, es el más antiguo de los barrios pobres, pues había surgido en la colonia con el origen de San José. ${ }^{40}$ Sus inicios se vinculan con las órdenes de Tomás López del Corral de que los vecinos habitaran en La Boca del Monte, mientras que diferenciaba entre los más acomodados y "los vecinos pobres sin hacienda de trapiche o ganado...". ${ }^{41}$

Se diferencia de La Puebla de Los Ángeles o La Puebla de los Pardos de Cartago (e incluso de Heredia) la cual estaba constituida por indígenas, mestizos y mulatos o pardos que quedaban marginados a vivir más allá de las zanjas que drenaban las ciudades; en ese caso nos encontramos 39 ANCR, AMSJ, 10445, 1893.

40 Briceño y otros, "Pobreza urbana", 106.

41 Cleto González y otros, San José y sus comienzos. Documentos fundamentales (San José, Costa Rica: Comisión Nacional de Conmemoraciones Históricas, 1987), 14. 
frente a una segregación centrada en un componente étnico.

La Puebla de San José, parece constituirse como un espacio de exclusión social para todos aquellos sectores que quedaron por fuera del proyecto habitacional y de desarrollo de la élite, desde los orígenes de la ciudad. Un aspecto que cabe indagar aún es la relación entre la segregación étnica y la segregación de clase social presentes en La Puebla josefina.

Existen referencias a La Puebla al menos desde 1759, según los escritos de Cleto González y Luis Felipe González citando a los protocolos coloniales. ${ }^{42}$ Abarcó los asentamientos que se establecieron al sur de la avenida central, desde la llamada Calle de La Puebla (Calle 4) hasta las inmediaciones de lo que actualmente constituye la iglesia de La Merced, el Hospital San Juan de Dios y el Barrio Santa Lucía. ${ }^{43}$

Luisa González, quien fue habitante de La Puebla, narra en Aras del suelo, su novela autobiográfica aspectos de la vida en esta comunidad:

“...En el barrio de La Puebla, situado en las vecindades de la escuela Porfirio Brenes, existieron por muchos años aquellas pulperías de nombres extraños y raros para nosotros: "El Acorazado de España”, "La Poupée”, "El Pelayo” (...) Allá por el año 1912, La Puebla era el barrio más pobre, más sucio, escandaloso y relajado de la capital. Zona donde crecían a sus anchas el vicio, la miseria y la prostitución". ${ }^{4}$

Una de las pulperías mencionada por Luisa, El acorazado de España, aparece en la siguiente fotografía de 1912, en la esquina de calle 4 y avenida 10, al final de esa cuadra está la escuela.

42 Quesada, “La modernización”, 30.

43 Briceño y otros, "Pobreza urbana", 106-107.

44 Luisa González, A ras del suelo (San José, Costa Rica: Editorial Costa Rica, 1977), 19. 


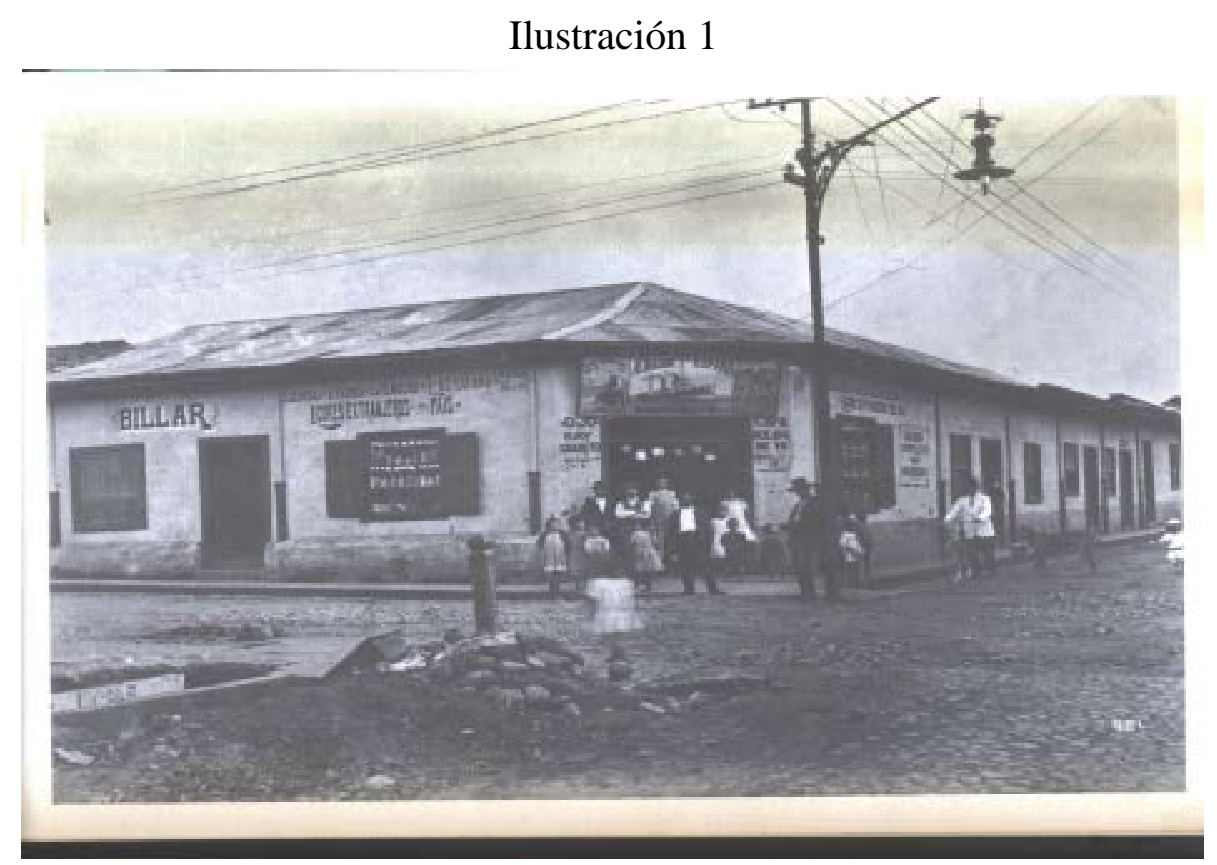

Fuente: Colección de fotografías, La Ciudad de San José 1871-1921, Banco Nacional de Costa Rica, San José, Costa Rica: Lehmann.

Las miradas externas al lugar permiten acercarse a cómo era visto y pensado ese espacio de la ciudad:

"Era parte de La Dolorosa que conocí en paredes y techo, y corría hasta Las Pilas, y lo que hoy es Barrio Cristo Rey. Era la residencia o zona de tolerancia para las muchachas alegres, nido de alegres guitarras, marimbas y acordeones las noches de los sábados y de domingos, con uno que otro apuñaleado, con coches a la puerta y alumbrada con linternas enormes, con una lámpara de canfín, cosa que logré ver de chiquillo". ${ }^{45}$

Otra caracterización la realiza el español Ignacio Trullas y Aullet (con el pseudónimo de Chantecler):

"La Puebla, como barrio orillero que es por excelencia, tiene las viviendas pobres y malsanas, todas de bajos, con patio comunicado: muchas falta de luz y aire respirable: en las calles, menos urbanizados que las del centro, crece la yerba y el zacate como si fuesen potreros; llenas de oyancos [sic] y piedras, parecen mapas en relieve de países deshabitados, donde el sol abrasa el

45 Macabeo Vargas, "Nombres viejo y curiosos de los barrios y vecindades de San José", en Del viejo San José, comp. Elías Zeledón (San José, Costa Rica: Editorial de la Universidad de Costa Rica, 2004), 143. 
medio día, y el viento levanta nubes de polvo que tapan la respiración, al caer la tarde". ${ }^{46}$

En La Puebla se asentaron los sectores excluidos del proyecto de ciudad que fue desarrollado en San José. Las referencias encontradas acerca del lugar remiten a la pobreza, la vida popular y la "corrupción social". En este sector desde sus orígenes, se ausentaron los servicios básicos como cañería, electricidad o lastreado, y fue un sitio de ubicación de la marginalidad urbana.

En La Puebla, a las dificultades socioeconómicas se impuso una significativa estigmatización social. A este sector de la ciudad se le atribuyó constantemente ser "problemático", fuente de los males citadinos que supuestamente provenían tanto del lugar como de sus habitantes: inseguridad, prostitución, enfermedades, vicios, hambre, juego, alcohol, y la miseria social.

En La Puebla se estableció la "zona de tolerancia", espacio de vida y ejercicio del comercio sexual, como lo mencionó Luisa González párrafos anteriores, y que era el sitio de donde probablemente en una conjunción de censura moralista y explotación se constituye el estigma acerca de la peligrosidad de todo el barrio, que se extendería a los nuevos asentamientos al sur: “...entre 1915 y algo menos de los años 20, la "zona de tolerancia" (...) habrá sido desplazada bastante al sur, por el $\mathrm{B}^{\circ}$ Keith, desde La Puebla; es decir, desde avs. 8 y 10, calle 12, aproximadamente, se habría trasladado al sur de la avenida $20 . . . "{ }^{47}$

\section{El Laberinto}

A principios del siglo XX cobra importancia El Laberinto, considerado como la primera propuesta de un barrio popular por iniciativa gubernamental, para dotar de lotes en San José a familias empobrecidas ${ }^{48}$ Originalmente se trataba de una hacienda cafetalera ubicada entre Avenida 12 y 20, y la Calle del Laberinto ( $3^{\mathrm{a}}$ sur). En 1893 Riotte y Jager elaboran una carta dirigida a la Municipalidad de San José solicitando la prolongación de una cañería en la finca El Laberinto, el terreno que donaron, para beneficio del vecindario y motivar así el establecimiento de población. ${ }^{49}$ Con el afán de promover la construcción en un sector de la ciudad que se encontraba en crecimiento, el 10 de mayo de 1905 el Estado emitió el decreto para la creación de "El Laberinto"; 50 se vendieron 23 lotes de aproximadamente 9 metros de frente por 25 de 46 Según Quesada, Chantecler residió en Costa Rica y trabajó como periodista en el diario La Prensa Libre, este extracto proviene de sus "Escenas Josefinas", siendo el único extranjero que hace mención a uno de los barrios populares al sur de la ciudad. Quesada, "La modernización”, 223.

47 Cerdas, "Condiciones de vida", 283-284.

48 Álvarez y Gómez, "San José de antaño”, 79.

49 ANCR, AMSJ, 005605, 1893.

50 ANCR, Congreso, 003027, 24-3-1905, Decreto Nº 4. Según ese decreto se faculta al Ejecutivo para 
fondo: 14 adquiridos por hombres y 9 por mujeres. ${ }^{51}$ Sin embargo “....aunque los lotes se dieron gratuitamente, no se daban fondos para la construcción de las viviendas y para muchas familias fue un proyecto imposible de realizar y con el tiempo perdieron sus propiedades...". 52

En esa zona, se ubicó un complejo de fábricas que dieron empleo a obreros de los alrededores; tuvo el mismo nombre (El Laberinto) y se localizó entre calle 1-5 y avenidas 18 y 20. Los terrenos en los que se ubicó eran propiedad de José C. Zeledón, ${ }^{53}$ que posteriormente pasaron a manos del fundador, propietario y director, el industrial Julio Alvarado Rodríguez. ${ }^{54} \mathrm{El}$ centro industrial estuvo conformado por fábricas que producían varios artículos: ${ }^{55}$ jabones, tejas, velas, telas, aserradero de maderas. ${ }^{56}$ Posteriormente algunas de esas fábricas se convirtieron en "Tejidos Saprissa". ${ }^{57}$

Cabe destacar que “...la creación del Laberinto marcó el inicio de la construcción de los barrios populares al sur, en las décadas siguientes..." ${ }^{58} \mathrm{El}$ establecimiento de barrios y asentamientos en esta zona de la ciudad vino de la mano con "...los aserraderos, la plaza, el tranvía y los negocios comerciales que, además de facilitar la adquisición de los productos, eran una fuente de trabajo para obreros, influyeron en la conformación de esta zona como residencia de personas de bajos recursos"; 59 esto ocurrió de la mano con la lotificación y venta de los terrenos del Dr. Alejandro Vargas Araya, cerca del lugar ocupado anteriormente por el Matadero Municipal (hoy San Cayetano). De esta manera la ciudad vería el surgimiento de Barrios como Keith, Carit y con la llegada del ferrocarril, el Pacífico". ${ }^{60}$

vender lotes a costarricenses pobres la finca inscrita en el Registro Público bajo el № 14846 al folio 158 tomo 228, situada en esta ciudad en el punto llamado El Laberinto.

51 Quesada, "La modernización”, 96.

52 Quesada, "La modernización”, 97.

53 Ibid.

$54 \quad$ ANCR, Serie Fotografía, N No 082781.

55 En 1876 ya existía registro de la existencia de esas fábricas, cuando don Francisco Gil solicita al Congreso Constitucional de la República de Costa Rica "se le conozca el privilegio exclusivo para fabricar jabón de reina en una instalación ó empresa que tiene establecida en el punto denominado "Laberinto", titulada "Fábrica de San José" por el tiempo de 10 años" ANCR, Serie Congreso, No 008619, 24 de julio 1876.

56 The Latin American Boureau, 1919, 165

57 Álvarez y Gómez, "San José de antaño", 79.

58 Quesada, "La modernización", 97.

59 Álvarez y Gómez, "San José de antaño", 74.

60 Según José Manuel Cerdas, el Diario de Costa Rica informaba en 1934 "que al suroeste de la capital se había formado una barriada que ya se extendía hasta el distrito de San Sebastián, con "gentes pobres modestas". "Quieren escuela y hay un lote donado por John M. Keith al efecto. Esa y otras extensiones hacia el sur fueron muy notorias y aceleradas. De esta manera surge el Barrio Keith, posteriormente llamado Cristo Rey. “Condiciones de vida”, 283-284. 
El testimonio de un zapatero refleja cómo se configuró la segregación y la vida en los años 40: "La mayoría de obreros ya vivían fuera de San José. Los de B Keith tuvieron que "brincar" a otro barrio que se formó por San Sebastián: Sagrada Familia. Se iban alejando por las casas cada vez más caras. Casas para pobres o zapateros en San José no se conseguían y se inició la labor de la Cooperativa ("La Familia") en los años 40 y del I.N.V.U. (Instituto Nacional de Vivienda y Urbanismo) en la década siguiente, pero construyendo fuera de San José”. ${ }^{61}$

La extensión de la zona comercial capitalina tuvo un impacto en la distribución espacial de los barrios para vivienda, por eso "...las viejas denominaciones y los propios barrios fueron desapareciendo ( $\mathrm{La}$ Puebla, Constructora, Chile de Perro, etc.). En otros casos los nombres cambiaron: Rincón de Cubillos por B Béxico, El Turrujal por Luján, Keith por Cristo Rey, etc. También aparecieron nuevos: Sagrada Familia, Los Pinos, Cuba, Güell, La Cruz, las distintas ciudadelas y urbanizaciones, etc". ${ }^{62}$

\section{Recursos y discursos}

Los discursos sobre los espacios de la ciudad fueron construidos en función de los recursos presentes o ausentes en ellos, la infraestructura y los depósitos que una sociedad hace sobre esos lugares, en términos tanto materiales como simbólicos; de allí la importancia que tuvieron las tendencias higienistas de la ideología liberal en la construcción de representaciones acerca de los sectores populares y sobre los excluidos, propiciando la estigmatización y una mayor marginación.

Con la consolidación de la cultura liberal burguesa, "la higiene política y moral era tan importante como la higiene física", ${ }^{63}$ por eso los higienistas plantearon la creación de un modelo de ciudad en el que su máxima preocupación fue la higiene y la salud, lo cual implicaba el control y vigilancia sobre la población y las condiciones de edificios y viviendas, la distribución del agua, el pavimento de las calles, la iluminación eléctrica. La limpieza se convierte en noción estructuradora de políticas y acciones que fueron plasmadas en el espacio y que vinieron a modificar forzosamente costumbres y patrones culturales. El ideal a alcanzar era la "ciudad higiénica, limpia y ordenada" para lo cual fue indispensable la instalación de una "red tecnológica urbana para el saneamiento". ${ }^{64}$

61 Cerdas, "Condiciones de vida", 289.

62 Ibid., 284.

63 Palmer, "Prolegómenos", 210.

64 Quesada, "La modernización”, 71. 
Si bien se promovieron cambios en todo lo concerniente a la vida urbana, lo que interesa rescatar aquí es el lugar otorgado a ciertas edificaciones y su contenido simbólico en la configuración de la urbe josefina. En el discurso "modernizador" o de "progreso" suelen ser vinculados con la vida: agua, vivienda, producción industrial, espacios recreativos, cultura. En contraposición, otros lugares son asociados con la muerte, la enfermedad, el peligro o la contaminación: el leprosario, el rastro, el reformatorio, el asilo, los cementerios, la cárcel, botaderos y crematorios (basura), el desagüe de la cañería (aguas servidas), etc. Inicialmente, en la ciudad de San José, esos "espacios profanos" fueron ubicados al sur de la ciudad.

El Leprosario o Lazareto constituyó desde 1830, una de las primeras instituciones de salud que contó con un edificio para atender a la población con lepra, se ubicó en el distrito Hospital. ${ }^{65}$ En 1845, en el mismo sitio, fue creado el Hospital San Juan de Dios, también al sur, con el objetivo de "...dar albergue por el Estado a varias categorías de pobres, como los discapacitados o impedidos físicos, los huérfanos y los locos o dementes, y a los enfermos pobres que no podían pagar la atención facultativa...". ${ }^{66}$ Mientras que la élite recibía al médico en sus domicilios, los sectores populares enfrentaron un hospital que fue el depósito de la exclusión de la ciudad y de la sociedad. El lugar hizo las de cárcel, manicomio, orfanato, asilo de incurables y ancianos, con funciones y espacios mezclados, situaciones que intentaron cambiar en $1878 .{ }^{67}$

En relación a las cárceles, fuera de San José, existía el presidio de San Lucas desde 1873, ubicado en la isla del mismo nombre en el Pacífico. En 1897, fue construida la Penitenciaría en San José, justo en el "extremo norte" de la "calle de La Puebla", distanciada físicamente de la ciudad por el paso del río Torres. Al igual que otras instituciones de control social, diferentes autores “... coinciden en que la cárcel moderna costarricense nació como resultado de las nuevas políticas de disciplinamiento que impuso la oligarquía cafetalera a finales del siglo XIX en donde la vigilancia y la segregación social se complementaron con el trabajo y disciplinamiento de las costumbres...". ${ }^{68}$

Otra directriz de la época señalaba que los mataderos debían construirse en las afueras de las 65 Vargas y Zamora, "El patrimonio histórico-arquitectónico", 42-43.

66 Miguel Guzmán, "Benefactores, pobres mendicantes y pobres vergonzantes: filantropía y caridad en las relaciones sociales de Costa Rica", en Pobreza e historia en Costa Rica. Determinantes estructurales y representaciones sociales del siglo XVIII a 1950, ed. Ronny Viales (San José, Costa Rica: Editorial de la Universidad de Costa Rica, 2005), 226.

$67 \quad$ Ibid., 229.

68 Juan José Marín Hernández, Prostitución, honor y cambio cultural en la provincia de San José de Costa Rica: 1860-1949, (San José, Costa Rica: Editorial de la Universidad de Costa Rica, 2007), 337. 
ciudades; ${ }^{69}$ el rastro terminó su construcción en 1900, razón por la cual fueron rectificadas las calles 24 y 25 sur para dar acceso al nuevo edificio, ${ }^{70}$ esto ocurrió en el Barrio Colección (posteriormente San Cayetano).

También pueden mencionarse otros elementos de infraestructura vinculados desde el discurso higienista a la muerte y a la contaminación que fueron construidos al sur: los cementerios, las Casas de Corrección (posterior Liceo de Costa Rica) y el Asilo Chapuí. ${ }^{71}$

En el acceso al agua es donde probablemente se refleja más claramente la segregación. Aunque se instalaron en la ciudad lavaderos y baños públicos dirigidos a la mayoría de personas, quienes no tenían acceso al líquido, en la instalación de la cañería por parte de la Municipalidad se evidenciaron favoritismos hacia los sectores adinerados y la exclusión de los barrios populares. Florencia Quesada afirma que en 1913 ante la solicitud de los vecinos de Carit para la instalación de la cañería a la Municipalidad, se alegó "falta de presupuesto", pero ese mismo año fueron instaladas 46 pajas de agua en el Barrio Aranjuez, 20 de ellas destinadas a lotes que ni siquiera estaban construidos, pero que el poseer el servicio aumentaba el valor sobre la propiedad. ${ }^{72}$ Cabe mencionar, además, que en 1907 la primera cloaca surge con la canalización de la acequia de las Arias hasta el nuevo rastro, ${ }^{73}$ desembocó en el sur, en el río María Aguilar.

A esa ubicación de esos lugares se suma el control y requisa constante de las vidas de los sectores populares por medio de medidas coercitivas; esto se daba, por ejemplo, a través de las inspecciones de salubridad a las "viviendas de pobres" y con las informaciones de pobreza las cuales, desde finales del XIX, eran utilizadas por las autoridades locales para corroborar la "condición real" de esos sectores, frente a la asistencia estatal o privada. ${ }^{74}$

Como puede verse cobra importancia que los lugares relacionados con la muerte, la locura, la enfermedad, el delito, la basura y los residuos fueran ubicados en el "sur", aspecto que evidencia la presencia de la exclusión en el espacio y constituye una decisión que tiene asidero en la

69 Vargas y Zamora, "El patrimonio histórico-arquitectónico", 148.

70 Quesada, "La modernización”, 95.

71 Quesada, "La modernización”, 94.

72 Ibid., 129.

73 Tirza Bustamante, La ciudad de San José (ensayo histórico), (San José: Costa Rica: Municipalidad de San José, 1996), 118.

74 Ronny Viales "El régimen liberal de bienestar y la institucionalización de la pobreza en Costa Rica, 1870-1930", en Pobreza e historia en Costa Rica. Determinantes estructurales y representaciones sociales del siglo XVIII a 1950 (San José, Costa Rica: Editorial de la Universidad de Costa Rica, 2005), 94. 
concepción de "higienización social", como lo denomina Steven Palmer, promovida desde el Estado a través del área de salud pública. ${ }^{75}$

\section{La ciudad neoliberal}

Como un fenómeno que se ha extendido en toda América Latina, los planes municipales y gubernamentales se encaminan a posicionar un modelo de ciudad acorde con el proyecto de la actual élite económica. Mario Lungo y Sonia Baires señalan la existencia de tres tipos de intervenciones urbanas que han contribuido a marcar y segregar los espacios urbanos en la actualidad:

1. "Los grandes proyectos de recuperación urbana, asociados, generalmente a la potenciación de procesos de grentification. La recuperación de centros históricos cabría encuadrarla dentro de este tipo de proyectos.

2. La construcción de grandes infraestructuras varias y centros comerciales, ligados con la relocalización de actividades productivas y servicios y con el comercio internacional e interregional, vinculado al proceso de globalización.

3. La creación de urbanizaciones cerradas en áreas de rentas altas y medio altas. Estos complejos residenciales adquieren formas variadas dependiendo de la ciudad y/o país del que se trate, conectándose con las nuevas redes viarias urbanas". ${ }^{76}$

Esos procesos se encuentran presentes en la ciudad de San José, al mismo tiempo en que la élite costarricense vuelve a pensar la ciudad con el proyecto neoliberal. A partir de los años 80, pero más aún en los 90 y en el inicio de siglo, la ciudad es retomada como centro de atención, espacio destinado a acoger el actual modelo económico.

El proyecto promovido por el municipio, que sintetiza las nociones a seguir hacia una ciudad neoliberal, se esboza en los programas de gobierno local ("San José: una Ciudad para Todos" (2003-2007), "San José: Más destino que camino" (2007-2011), etc.), los cuales plantean, como uno de los ejes de mayor interés para este trabajo, la "Renovación Urbana y Repoblamiento del

75 En: Javier Rodríguez, "El Estado en Costa Rica, la iniciativa pública y privada frente al problema de la pobreza urbana. San José (1890-1930)", Anuario de Estudios Centroamericanos (Costa Rica), 26, n. 1-2 (2000).

76 Mario Lungo y Sonia Baires. Socio-spatial Segregation and Urban Land Regulation in Latin American Cities", en Segregation in the City, Seminario organizado por el Lincoln Institute of Land Police (LILP), Cambidge, Massachussets, 25 a 28 julio 2001. Citados en: Fernando Díaz, María Luisa Lourés; Carla Rodríguez y Verónica Devalle, "Ciudad, territorio y exclusión social. Las políticas de recualificación urbana en la ciudad de Buenos Aires”, Reis Revista española de investigaciones sociológicas (España), 103 (2003), http://rua.ua.es:8080/ bitstream/10045/2774/1/REIS_103_071167997490252.pdf (Fecha de acceso: 14 de marzo de 2008). Resaltado en el original. 
Casco Central de la Ciudad" que busca atender las problemáticas y "convertir a San José en LA CIUDAD PARA TODOS”. Según indican, las orientaciones de estos programas se encaminan a generar las condiciones básicas necesarias, para que el casco central josefino "recupere su funcionalidad habitacional, comercial y de servicios, así como su competitividad urbana, su tejido social y su calidad general de vida". ${ }^{77}$

Para ello se busca hacer de San José una ciudad competitiva, repoblada por la élite. Dos ejes son transversales en ese modelo: la promoción de inversión en "el centro" de tipo inmobiliario y turístico y el impulso al traslado de la élite al centro de la ciudad; para ello se han generado condiciones como la peatonización, pero más aún la construcción en vertical de los nuevos sitios exclusivos. En los documentos municipales se indica que: "El desarrollo del repoblamiento, depende, en gran medida, de la visión del sector privado y sus distintos actores: propietarios de tierras, inversionistas, desarrolladores y clientes finales". ${ }^{78}$

El mismo plan dictamina quiénes pueden habitar la ciudad, a través del establecimiento de una nueva segregación. Esto ocurre, no sólo por la presión sobre el uso de la tierra, los altos costos y la exclusión del centro de los sectores populares, ${ }^{79}$ sino también a través de la promoción de proyectos de alojamiento que se encuentran muy lejos del alcance de la mayor parte de la población. Se tiene definido así, según la Municipalidad, un "público meta para estas soluciones habitacionales en altura: funcionarias y funcionarios de instituciones públicas y de empresas privadas vinculadas a los servicios financieros, el comercio y, principalmente, el turismo". Y continúa: "El propósito es que sean personas jóvenes, profesionales o técnicos, con un nivel adquisitivo medio, que estén interesados en vivir cerca de sus lugares de trabajo y que, eventualmente, se verían beneficiados con la oferta de la ciudad en entretenimiento, arte, cultura, etcétera", ${ }^{80}$

Para cumplir con el perfil ese sector debe "tener acceso a un crédito bancario para financiar su solución habitacional en altura, dentro de los desarrollos que la empresa privada lleve a cabo en el centro". ${ }^{81}$

\section{Esta propuesta no sólo evidencia, la ya conocida en otras épocas vinculación entre el sector}

77 Johnny Araya, Programa de gobierno “San José: una Ciudad para Todos”, Municipalidad de San José (2003-2007).

78 Municipalidad de San José, Explicación sobre el Plan de Regeneración y Repoblamiento de la Ciudad de San José, http://www.msj.co.cr/expli_plan_regen_repob_sanjose.pdf, consulta: 1 de mayo 2008.

79 El plan de repoblamiento hace la siguiente aclaración: "Dentro de los planes del ayuntamiento, no está el desarrollo de proyectos de vivienda de interés social para la capital".

80 Municipalidad de San José, "Explicación”.

81 Ibid. 
público y el sector construcción e inmobiliario, sino los sujetos que se aspira que vivan en la ciudad neoliberal. Basta conocer uno de los seis proyectos de este tipo que promueve el municipio en el centro histórico de San José: Lahmann 1060. Se trata de condominios con un valor de $\$ 75.000$ a $\$ 90.000$, con cuotas de alquiler de $\$ 500$ a $\$ 600$ mensuales. $^{82}$

Asimismo, ese modelo de ciudad piensa ser impulsado por modificaciones en el transporte que son presentadas con la respaldada idea de facilitar el movimiento urbano, para ello se construirán carreteras de circunvalación que atravesarán distintos puntos en los alrededores de la ciudad, y en algunos casos, cosa no prevista por la ingeniería, segmentarán a barrios históricos y recientemente constituidos. Pero la clave parece encontrarse en la creación de rutas periféricas con el objetivo de reducir el acceso de vehículos y la presencia de emisiones en el centro repoblado por la élite.

Sin lugar a dudas, esta ciudad no puede ocultar las formas en las cuales se manifiestan en el espacio la exclusión social y la inequidad cada vez mayores. De allí el surgimiento y la existencia de comunidades como La Carpio, ubicada en La Uruca, al noroeste de San José. Por eso, coincidimos con Carlos Sandoval cuando plantea que La Carpio es un sitio estratégico desde donde aproximarse a la Costa Rica contemporánea. ${ }^{83}$

Esta comunidad surgió entre 1993 y 1994 de una toma de tierras propiedad, en ese entones, de la Caja Costarricense de Seguro Social. En ella habitan aproximadamente 23 mil personas y la mitad de ellas son costarricenses, un 49\% nicaragüenses y el resto de otras nacionalidades. La Carpio es claramente un ejemplo de la segregación actual en la ciudad de San José, por su ubicación, origen y dificultades en el acceso a servicios básicos y recursos, pero a esto se suma la estigmatización, pues le es atribuida la peligrosidad, la violencia y la contaminación. ${ }^{84}$

La discriminación vivida por sus habitantes se vincula al amarillismo mediático y a la instauración de la exclusión en el espacio, la comunidad surge ante la imposibilidad de miles de familias de pagar alquiler o construirse una vivienda. A esto se agrega que en el año 2000 en el lugar fue instalado el relleno de basura que recibe la mayor parte de los desechos del Área Metropolitana de San José. Además, existen planes de Acueductos y Alcantarillados de establecer una planta de

82 Gloriana Gómez, "Un proyecto de lofts propone una nueva forma de habitar la ciudad", Suplemento Informativo Inmobiliario, La Nación,7 de julio del 2007.

83 Carlos Sandoval, La Carpio. La experiencia de segregación urbana y estigmatización social, Instituto de Investigaciones Sociales, Universidad de Costa Rica, 2005. http://www.iis.ucr.ac.cr/pagWeb/investigacion/ cultInstSubj.php (Fecha de acceso 30 de julio del 2006).

84 Sandoval, "La Carpio". 
tratamientos de aguas servidas en la comunidad. ${ }^{85}$

La presencia de la basura, crea una construcción imaginaria sobre el lugar y sus habitantes, vinculada al desecho, a lo rechazado, a la suciedad y la contaminación, elementos que se reproducen en la discriminación que enfrenta la población. Es posible tener un acercamiento a la estigmatización experimentada por las personas de la comunidad a través del relato de Juan, un joven de La Carpio:

“...A veces, estás en el trabajo, en donde estés, en el parque, en el restaurante, hacés un nuevo amigo, te pregunta: ‘¿y vos de dónde sos?’, soy de La Carpio, quizás la primera reacción sea: ‘usted es nica’ o ‘ahí sólo nicas viven’, como primera reacción; segunda reacción, es: 'ahí sí es un hueco, un hueco hediondo, ahí sólo ladrones hay, sólo maleantes, yo ahí ni me invite a ir porque ahí me mandan chingo', en estilo de broma pero si uno ya en plan les dice: te invito a mi casa, no te aceptan ir a la casa, porque, o sea, tienen una reputación de Carpio absolutamente por los suelos y no es así.

"La mayoría de la gente de Carpio es trabajadora, tranquila, lo que quiere es salir adelante, tanto los inmigrantes como los ticos, no están ahí porque quisieran estar, están porque la pobreza los ha empujado a vivir ahí, pero eso no les ha quitado las ganas de trabajar ni las ganas de vivir, ahí la gente quiere superarse" ${ }^{86}$

A pesar de las dificultades buena parte de los servicios como el agua, la electricidad y la escuela fueron conseguidos por la gestión, esfuerzo y presión de los vecinos y vecinas de La Carpio; ${ }^{87}$ posiblemente la mayor de las luchas dadas fue en función de sus viviendas y en contra de la marginalización, como lo indica Juan, que reciben al solicitar empleo, matrícula en los colegios o al invitar a las personas a llegar a la comunidad.

Con este ejemplo posiblemente resulte más claro comprender cómo se da la segregación en la ciudad a través de la desigual distribución de los recursos espaciales, materiales y simbólicos; asimismo, es posible visualizar cómo la exclusión se materializa en formas que propician el sufrimiento social, legitimadas desde las instancias de poder y el ámbito empresarial.

85 Sandoval, "La Carpio".

86 Carlos Sandoval, Mónica Brenes, Karen Masís, Laura Paniagua y Esteban Sánchez (ed), Nuestras vidas en Carpio. Aportes para una historia popular (San José, Costa Rica: Editorial Universidad de Costa Rica, 2007), 160.

87 Ibid. 


\section{Reflexiones finales}

Este trabajo es un esfuerzo inicial por analizar continuidades y particularidades entre el proyecto de élite presente en la ciudad liberal y el que se encuentra en la ciudad neoliberal. El recorrido realizado a través de estas páginas ha explicitado algunos vínculos e interpretaciones acerca del ejercicio del poder, la ubicación espacial y la geografía de la exclusión. Se esclarece someramente cómo el espacio responde a una construcción histórico-política mediada por las formas de producción y los usos dados a la tierra y la especulación.

En San José, desde los orígenes de la ciudad, la burguesía se ubicó en un lugar diametralmente opuesto a los sectores populares, dividiendo y jerarquizando el espacio; ${ }^{88}$ como se pudo constatar, este proceso ha sido una constante desde finales del siglo XIX y durante todo el siglo XX. El sur y el noroeste se constituyeron como los lugares segregados históricamente en San José, surgen con la ciudad misma, como el lugar de vida para los sectores populares y excluidos y con el tiempo han sido expulsados paulatinamente del centro histórico de la ciudad, hasta posicionarse en otros sectores cada vez más alejados del centro: La Carpio, Los Guido, Pavas, Los Cuadros, etc. Igualmente, en algunos casos sectores históricamente marginados conservan su constante poblacional en términos de clase: Luna Park, Cristo Rey, Barrio Los Ángeles, entre otros.

En la ciudad neoliberal se perfila la cada vez más marcada segregación entre barrios excluidos y barrios exclusivos, mientras la élite promueve desde distintas vías la privatización del espacio urbano, en especial el centro histórico y en relación directa con la habitabilidad en la ciudad. Como el objetivo simplemente ha sido delinear una aproximación a la temática analizada, más que plantear conclusiones es preferible plasmar algunas interrogantes por explorar. Puede indagarse sobre las semejanzas y diferencias entre las viejas y las actuales formas de segregación en la ciudad de San José, en especial para dilucidar cuál era la composición social de los barrios excluidos en los orígenes de la ciudad. De allí que podría aclararse la tensión entre el componente étnico y el de clase presentes en la segregación de barrios como La Puebla.

Otro aspecto que queda por profundizar es el vínculo entre proletariado y marginalidad, presente en los diferentes barrios de la capital. No encontramos en San José, barrios exclusivamente obreros, sino que en los mismos estuvieron presentes diversidad de sectores excluidos al extremo, éstos últimos vinculados a la prostitución, las drogas, y otras actividades perseguidas.

$88 \quad$ Salazar, "Formación del espacio", 102. 
En relación a este punto, se plantea que el origen mismo del Sur es una manifestación de exclusión social; asimismo, la estigmatización enfrentada por "el Sur" se vinculó originariamente con la presencia de lugares rechazados dentro del discurso liberal de progreso, pero que eran a la vez absolutamente indispensables para la ciudad. El recorrido por la ubicación y distribución de los recursos ha permitido una lectura de la exclusión en términos geográficos, sociales y simbólicos en torno al espacio urbano.

Y, finalmente, cabría preguntarse por el espacio ocupado en la actualidad por lo que fue conocido como La Puebla. Es probable que aún exista la "zona de tolerancia", no sólo referida a prostitución sino también a comercialización de diversidad de productos. Un sector aún temido por buena parte de los transeúntes josefinos, que ha resistido al empuje del comercio y los servicios y aún guarda entre sus calles, casas, colores, olores y pasajes mucha historia, hoy una historia migrante. 